\title{
A new species of Entolomataceae with cuboidal basidiospores from the São Paulo Metropolitan Region, Brazil
}

\section{Karstedt $\mathbf{F}^{\mathbf{1}}$ and Capelari $\mathbf{M}^{\mathbf{1}}$}

${ }^{1}$ Instituto de Botânica, Núcleo de Pesquisa em Micologia, Caixa Postal 3005, 01031-970 São Paulo, SP, Brazil

Karstedt F, Capelari M 2015 - A new species of Entolomataceae with cuboidal basidiospores from São Paulo Metropolitan Region, Brazil. Mycosphere 6(1), 69-73, Doi 10.5943/mycosphere/6/1/8

Abstract

A new species of Entolomataceae with cuboidal basidiospores, from Reserva Biológica de Paranapiacaba, is described, illustrated and discussed.

Key words - Entoloma - taxonomy

\section{Introduction}

Most Entolomataceae (Entoloma s.l.) species are characterized by their peculiar shaped basidiospores that are cuboidal to multiangular, iso- to heterodiametric, and have four to nine angles in profile.

The cuboidal basidiospores have six quadrangular facets, comprising a depressed adaxial facet, a dihedral pair of lateral facets meeting in the apico-adaxial region, a large abaxial facet, and a dihedral pair of lateral facets that form the basidiospore base (Pegler \& Young 1978, 1979).

There are 14 species with cuboidal basidiospores cited for Brazil: Entoloma caribaeum (Pegler) Courtec. \& Fiard (Coimbra et al. 2013), Entoloma dragonosporum (Singer) E. Horak (Singer 1965, Horak 1982, Singer \& Aguiar 1986, Meijer 2001, 2006, Wartchow 2006, Coimbra et al. 2013), Entoloma lycopersicum E. Horak \& Singer (Horak 1982), Entoloma murrayi (Berk. \& M.A. Curtis) Sacc. (Sobestiansky 2005, Meijer 2006), Entoloma pinnum (Romagn.) Dennis (Putzke \& Cavalcanti 1997, Meijer 2006 as cf.), Entoloma viscaurantium E. Horak \& Singer (Horak 1982), Rhodophyllus fraternus Singer (Singer 1973, Horak 1976, 1977), Inocephalus azureoviridis (E. Horak \& Singer) Karstedt \& Capelari (Horak 1982, Souza \& Aguiar 2004 as cf., Karstedt \& Capelari 2013), Inocephalus cervinus Karstedt \& Capelari (Karstedt \& Capelari 2013), Inocephalus dennisii (E. Horak) Karstedt \& Capelari (Capelari 1989 as cf., Karstedt \& Capelari 2013), Inocephalus tenuis Karstedt \& Capelari (Karstedt \& Capelari 2013), Inocephalus virescens (Berk. \& M.A. Curtis) Largent \& Abell-Davis (Pegler 1997, Alves \& Nascimento 2012, Karstedt \& Capelari 2013), Inopilus kamerunensis (Bres.) Pegler (Pegler 1997) and Nolanea avilana Dennis (Capelari 1989 as cf., Meijer 2006 as aff., Coimbra et al. 2013). The last seven have been collected in the state of São Paulo, and two (I. azureoviridis and I. cervinus) occur in Reserva Biológica de Paranapiacaba.

To describe the new species this work adopted the Entoloma sensu lato concept, which includes all species with basidiospores that are angular in all views (Noordeloos \& Gates 2012).

\section{Materials \& Methods}

The new species was collected during a taxonomic survey of Reserva Biológica de 
Paranapiacaba, an Atlantic Forest remnant in Santo André City, in the São Paulo Metropolitan Region, São Paulo State, Brazil. The macroscopic decsriptions of basidiomata was baed on fresh material. Color terms are according Küppers (2002). The microscopic analyses and SEM preparations used follow those presented in Karstedt \& Capelari $(2010,2013)$. The specimen was deposited at SP (Thiers 2014).

\section{Results}

\section{Taxonomy}

Entoloma largentianum Karstedt \& Capelari, sp. nov.

Figs $1-2$ MycoBank 810790

Etymology - in honor of David Lee Largent for his contribution to knowledge of Entolomataceae.

Pileus $40 \mathrm{~mm}$ diam., convex-umbilicate, brown (near $\mathrm{N}_{60} \mathrm{Y}_{90} \mathrm{M}_{50}$ ) slightly reddish, hygrophanous, surface glabrous, translucent-striate at margin, margin slightly irregular. Pileus context thin. Lamellae decurrent, narrow, moderately close, grayish pink $\left(\mathrm{N}_{30} \mathrm{Y}_{20} \mathrm{M}_{30}\right)$, with 2-3 series of lamellulae, smooth margin, the same color as the faces of the lamella. Stipe $43 \times 6 \mathrm{~mm}$, cylindrical, centrally attached, cream (beige), longitudinally striate, slightly fibrillose, fibrous, hollow, base tomentose, mycelium white. Basidiospores cuboidal, with six faces each of which is quadrangular, 7.5-8.7 × 7.5-8.7(-10) $\mu \mathrm{m}\left[\mathrm{x}_{\mathrm{m}}=8.65( \pm 0.3) \times 8.26( \pm 0.59) \mu \mathrm{m}, \mathrm{Q}=1-1.16, \mathrm{Q}_{\mathrm{m}}=\right.$ $1.05( \pm 0.07), \mathrm{n}=20]$ and $10-11.2 \times 10-11.2 \mu \mathrm{m}\left[\mathrm{x}_{\mathrm{m}}=10.89( \pm 0.55) \times 10.57( \pm 0.62) \mu \mathrm{m}, \mathrm{Q}=1-\right.$ $\left.1.12, \mathrm{Q}_{\mathrm{m}}=1.03( \pm 0.05), \mathrm{n}=20\right]$ in diagonal, slightly pinkish brown, thin-walled. Basidia clavate, 35-45 $\times 10-12.5 \mu \mathrm{m}(\mathrm{n}=20)$, hyaline, thin walled, with 4 sterigmata. Cheilocystidia and pleurocystidia dispersed, fusoid, fusoid-ventricose, ventricose, ventricose-rostrate, sometimes collapsed, $51-75 \times 12.5-21 \mu \mathrm{m}(\mathrm{n}=13)$, hyaline or slightly brownish with brown intracellular pigment, thin-walled. Pseudocystidia absent. Lamellae trama comprising subparallel hyphae, cylindrical or inflated, sometimes branched, 3.7-12.5 $\mu \mathrm{m}$ diam. $(\mathrm{n}=20)$, hyaline, thin-walled, a few septa, much branched hyphae in the subhymenium. Pileal trama comprising radially entangled hyphae, cylindrical, cylindric-inflated, mostly collapsed, 3.7-18 $\mu \mathrm{m}$ diam. $(\mathrm{n}=10)$, hyaline, thinwalled, septate. Pileipellis comprising prostrate and slightly entangled hyphae, cylindrical, 5-17.5 $\mu \mathrm{m}$ diam. $(\mathrm{n}=20)$, hyaline, thin-walled; terminal hyphae prostrate, slightly clavate or cylindricalclavate. Stipetipellis a cutis, with cylindrical hyphae, 2.5-6.2 $\mu \mathrm{m}$ diam. $(\mathrm{n}=20)$, hyaline or straw yellow, thin-walled, septate. Clamp-connections present. Refractive hyphae absent.

Habitat - solitary, on soil.

Known distribution - in tropical region, in Atlantic Forest.

Material examined - Brazil, São Paulo State, Santo André, Reserva Biológica de Paranapiacaba, 23 March 2009, M. Capelari \& L.A. Silva Ramos 4450 (SP) Holotype.
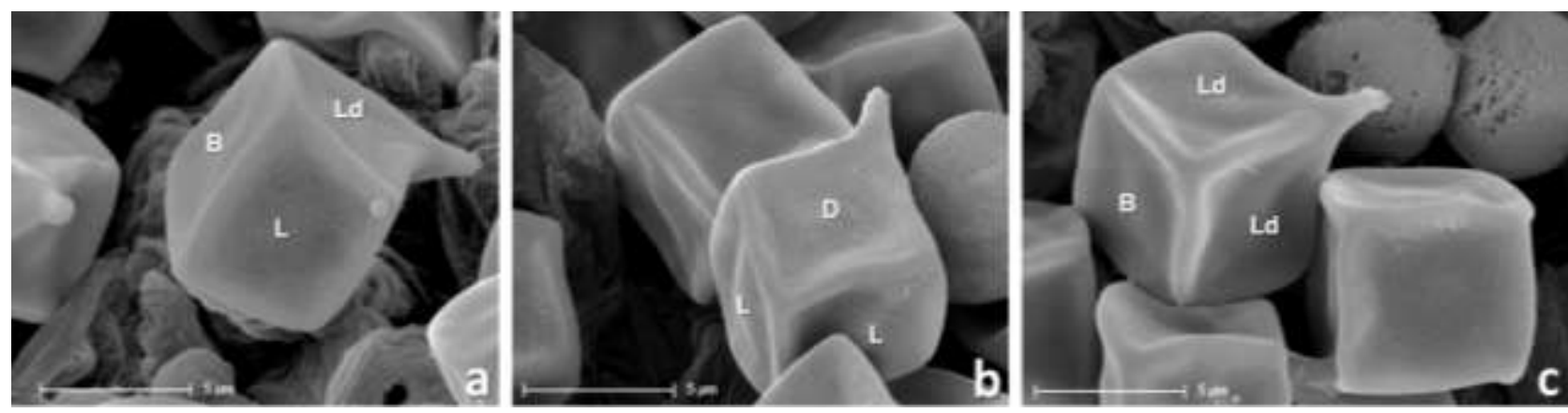

Fig. 1 - SEM of Entoloma largentianum basidiospores. B: abaxial facet, D: adaxial facet, L: lateral facets, Ld: dihedral pair of lateral facets. Scale: a-c: $5 \mu \mathrm{m}$. Photos by F Karstedt. 


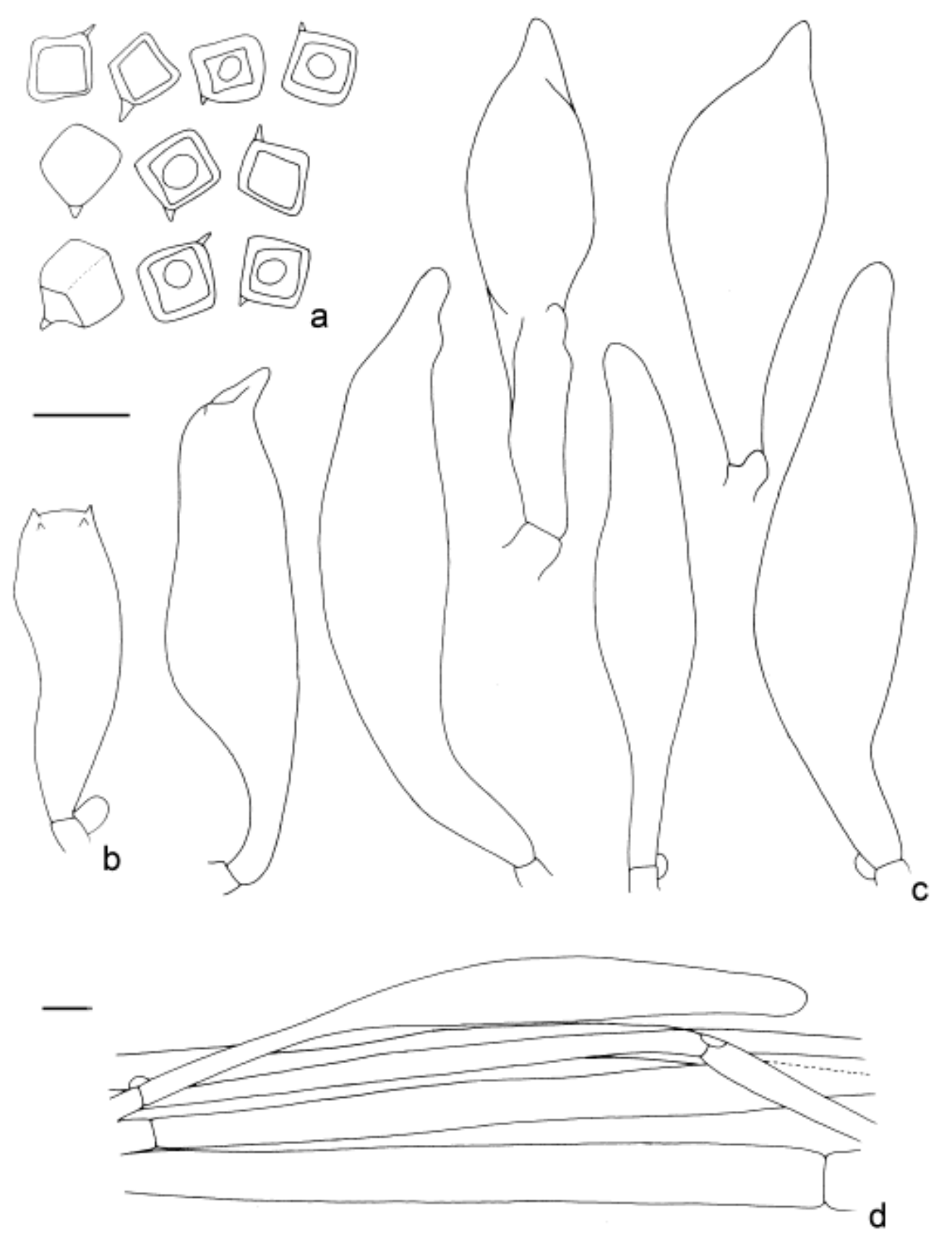

Fig. 2 - Entoloma largentianum (MC4450): a. basidiospore; b. basidia; c. cheilocystidia; d. pileipellis. Scales: a-d: $10 \mu \mathrm{m}$. Drawings by F Karstedt.

\section{Discussion}

All species with cuboidal basidiospores cited for Brazil differ from Entoloma largentianum because they have a convex or conic pileus, adnate or adnexed lamellae and cylindric or clavate cheilocystidia, instead of an umbilicate pileus, decurrent lamellae and fusoid cystidia.

The only species that resemble Entoloma largentianum, because they have omphalinoid basidiomata (with an umbilicate pileus and decurrent lamellae), cuboidal basidiospores and fusoid cystidia, are Leptonia omphalinoides Largent from Australia and Entoloma infundibuliforme Petch from Sri Lanka.

Leptonia omphalinoides differs from E. largentianum by its lignicolous habit, smaller basidiomata, $6-11 \mathrm{~mm}$ diam. pileus, pileus surface that is minutely squamulose with squamules that are erect towards the margin, and smaller basidiospores that measure 4.6-8.4 × 3.7-6.7 $\mu \mathrm{m}$ (Largent et al. 2013). 
Entoloma infundibuliforme Petch sensu Horak (1976) differs by having a pileus surface that is densely covered with fibrillose-squamous scales in the central region and by its smaller basidiospores $(5.5-8 \mu \mathrm{m})$. The material determined by E. Horak as E. infundibuliforme (1976, ZTMyc42836, old number ZT72/487) was analyzed and cuboidal basidiospores and fusoid cystidia were observed. However, collections of this species, including the type, need to be reviewed because Horak (1976) described the species with cuboidal basidiospores and fusoid cystidia and treated E. infundibuliforme Petch as a synomyn of Entoloma infundibuliforme Hesler (a nomen rejiciendum that was given a new name, Entoloma perumbilicatum Hesler). Further, Pegler (1986) mentioned that this species has pentagonal and square basidiospores in profile and fusoid cystidia but previously (in 1978) he had described the same collection with the same basidiospore shape but without cheilocystidia. Additional studies are needed to determine whether E. infundibuliforme has six faces quadrate or some faces pentagonal basidiospores, or if this species has two types of basidiospores.

\section{Acknowledgements}

The authors thank FAPESP (Fundação de Amparo à Pesquisa do Estado de São Paulo 2010/10218-5) for the financial support.

\section{References}

Alves MH, Nascimento CC. 2012 - Entoloma (Sacc.) E Horak ex Courtec. 1986 - (Agaricales: Entolomataceae): The first record for the Caatinga biome, Ceará, Brazil. Check List 8, 577-580.

Capelari M. 1989 - Agaricales do Parque Estadual da Ilha do Cardoso (exceto Tricholomataceae). Master's thesis, Universidade de São Paulo, São Paulo.

Coimbra VRM, Wartchow F, Gibertoni TB. 2013 - Studies on Entoloma (Agaricales, Basidiomycota) in the Atlantic Forest, Northeast Brazil. Nova Hedwigia 97, 139-157.

Horak E. 1976 - Additions to "On cuboid-spored species of Entoloma". Sydowia 29, 289-299.

Horak E. 1977 - Entoloma in South America. I. Sydowia 30, 40-110.

Horak E. 1982 - Entoloma in South America. II. Sydowia 35, 75-99.

Karstedt F, Capelari M. 2010 - New species and new combinations of Calliderma (Entolomataceae, Agaricales). Mycologia 102, 163-173.

Karstedt F, Capelari M. 2013 - Inocephalus (Entolomataceae, Agaricales) from São Paulo State, Brazil. Nova Hedwigia 96, 279-308.

Küppers, H. 2002 - Atlas de los colores. Editorial Blume, Barcelona.

Largent DL, Bergemann SE, Abell-Davis SE, Kluting KL, Cummings GA. 2013 - Five Leptonia species from New South Wales and Queensland, Australia. Mycotaxon 125, 11-35.

Meijer AAR. 2001 - Mycological work in the Brazilian State of Paraná. Nova Hedwigia 72, 105159.

Meijer AAR. 2006 - Preliminary list of the macromycetes from Brazilian State of Paraná. Boletim do Museu Botânico Municipal 68, 1-59.

Noordeloos ME, Gates GM. 2012 - The Entolomataceae of Tasmania. Fungal Diversity Research Series 22, 1-400.

Pegler DN, Young TWK. 1978 - Entolomataceae Kotl. \& Pouz. World Pollen and Spore Flora 7, $1-32$.

Pegler DN, Young TWK. 1979 - Spore form and phylogeny of Entolomataceae (Agaricales). Sydowia 8, 290-303.

Pegler DN. 1978 - A revision of Entolomataceae (Agaricales) from India and Sri Lanka. Kew Bulletin 32, 189-220.

Pegler DN. 1986 - Agaric flora of Sri Lanka. Kew Bulletin Additional Series 12, 1-496.

Pegler DN. 1997 - The Agarics of São Paulo, Brazil: an account of the agaricoid fungi (Holobasidiomycetes) of São Paulo State, Brazil. Royal Botanic Gardens, Kew. 
Putzke MTL, Cavalcanti MA. 1997 - O gênero Entoloma (Fr.) P. Kumm. (Entolomataceae, Agaricales, Basidiomycota) no Rio Grande do Sul, Brasil. Caderno de Pesquisa Série Botânica 9, 3-65.

Singer R, Aguiar IA. 1986 - Litter decomposing and ectomycorrhiza Basidiomycetes in an Igapo Forest. Plant Systematics and Evolution 153, 107-117.

Singer R. 1965 - Interesting and new Agaricales from Brazil. Atas do Instituto de Micologia 2, 1559.

Singer R. 1973 - Diagnosis Fungorum Novorum Agaricaliam III. Sydowia 7, 1-106.

Sobestiansky G. 2005 - Contribution to a macromycete survey of the States of Rio Grande do Sul and Santa Catarina in Brazil. Brazilian Archives of Biology and Technology 48, 437-457.

Souza HQ de, Aguiar IJA. 2004 - Diversidade de Agaricales (Basidiomycota) na Reserva Biológica Walter Egler, Amazonas, Brazil. Acta Amazonica 34, 43-51.

Thiers B. 2014 [continuously updated] - Index Herbariorum: A global directory of public herbaria and associated staff. New York Botanical Garden's Virtual Herbarium. http://sweetgum.nybg.org/ih/

Wartchow F. 2006 - The neotropical Entoloma dragonosporum (Agaricales, Basidiomycota): New record from northeast Brazil. Biociências 14, 93-94. 